\title{
Pituitary Macroadenoma (Fungal Hyphae): A Case Report and Literature Review
}

\author{
Samia Saleem ${ }^{1 *}$, Hajra Sarwer ${ }^{2}$, Muhammad Afzal $^{3}$, Awais Jamil ${ }^{4}$ \\ ${ }^{1}$ BSN (Student), Lahore School of Nursing, The University of Lahore, 1- Km Raiwind Rd, Sultan Town, Lahore, Punjab, Pakistan \\ ${ }^{2}$ Nursing Instructor at LSN (OUL), Lahore School of Nursing, The University of Lahore, 1- Km Raiwind Rd, Sultan Town, Lahore, Punjab, Pakistan \\ ${ }^{3}$ Professor at LSN (UOL), Lahore School of Nursing, The University of Lahore, 1- Km Raiwind Rd, Sultan Town, Lahore, Punjab, Pakistan \\ ${ }^{4}$ Nursing Manager, Lahore School of Nursing, The University of Lahore, 1- Km Raiwind Rd, Sultan Town, Lahore, Punjab, Pakistan
}

\begin{tabular}{ll}
\hline DOI: $10.36348 /$ sjnhc.2019.v02i12.004 & | Received: 20.11.2019| Accepted: 27.11 .2019 | Published: 20.12 .2019 \\
*Corresponding author: Samia Saleem &
\end{tabular}

Abstract

The Aspergillosis of the Paranasal sinuses is a well-recognized form of fungal infection, the involvement of the pituitary gland by aspergillosis is extremely rare. In which the main pathogen of the fungal seller is aspergillus classes. The pituitary infectious fungi consisted of different groups and dimorphic fungi. The leading pathogen of fungal seller abscess is the type of aspergillus. The possible route of infection through sphenoid sinus with a thin seller roof. A pituitary tumor differentiates through its size. Pituitary tumors undesirably are known to grow in the sphenoid bone, cavernous sinus, mid-nasal ductus, and left cerebral hemisphere. In our case presentation patient presented with pituitary macroadenoma, which diagnosed through magnetic resonance imaging. Presented with nasal mass, and acromegaly features headache. Right eye vision loss. Through endoscopy, biopsy report shows the nasal fungal infection. Surgical treatment, the trans-sphenoidal procedure will be planned as recommended in literature reviews.

Keywords: Pituitary Macroadenoma, Nasal obstruction. Optic Chiasm, Fungal Hyphae.

Copyright @ 2019: This is an open-access article distributed under the terms of the Creative Commons Attribution license which permits unrestricted use, distribution, and reproduction in any medium for non-commercial use (NonCommercial, or CC-BY-NC) provided the original author and source are credited.

\section{INTRODUCTION}

The etiologically of intracranial vascular contamination because of fungal infection is extremely uncommon. Furthermost cases occur in immunocompromised patients with hostile fungal disease, most commonly originating in the paranasal sinuses [1]. Since the first case pituitary aspergillus reported by Simmonds in 1914. The infecting fungi can be grouped into molds, yeasts, and dimorphic fungi.

The core pathogen of fungal seller infection is aspergillus classes. Aspergillus remain universal fungi produce in soil and organic materials and can start saprophytic progression inside the respiratory tract after inhalation [2].

The pathophysiologic pathway responsible for hypothalamic-pituitary dysfunction following acute meningitis is not fully unstated. In some patients, antipituitary and anti-hypothalamus antibodies are noticed. It is planned that acute infection aggravates an autoimmune process and may cause axonal injury with consequent neuroendocrine dysfunction (CNS infection) [3]. Initial identification and treatments are significant, and it is accordingly significant study the likelihood of seller aspergillosis in patients without primary risk factors. Grocott's methenamine-silver stain (GMS) optimistic for septated hyphae growths in which the opportunity of an Aspergillus diagnosis and PCR (Polymerase Chain Reaction) can be used as a confirmatory test.

Discretely adapted medical interventions with oral voriconazole seems to be effective after surgical excision. The Seller aspergillosis is an uncommon illness which is often originally misdiagnosed as an adenoma [4]. Pituitary aspergillosis has an extremely rare manifestation of invasive aspergillosis. A contrast MRI can often, but not always, help in suspecting this diagnosis. A trans-sphenoidal approach with debridement of the lesion is recommended. The optimum duration of therapy is unknown [5]. In this presenting case report, patient was admitted with sphenoid sinus infection, inflammatory signs of seller mass extension, optic chiasm involvement. Therefore, assumed that the pituitary fossa aspergillus contagion or infection was secondary to sphenoid sinus infection. 


\section{CASE PRESENTATION}

A 36 years old female client was presented as out-patient department, with complaint of headache, blurred vision, nasal obstruction, amenorrhea, acromegaly features, and high blood glucose levels $>300 \mathrm{mg} / \mathrm{dl}$. Her complaint duration was 9 months. She had been seeking health care from district hospitals for nasal obstruction, and headache. She was literate (matriculation level). She had married since 7years, even no kids or history of conceived pregnancy. Amenorrhea had been started 2 years back. She was a housewife. She had a history of the surgical procedure of appendicectomy 10years back. In major medical problems history of diabetes Insipidus, Insulin dependent. Recent vital signs were recorded in normal ranges. No significant history of weight loss or gain. No history of food or drug allergy. She had no significant family history including (genetical, communicable and no-communicable diseases).

Physical examination has revealed typical acromegalic features in her face and extremities. Hard skin surface from palm of the hand soles. Right sided bulging eye. Cranial nerves intact.

After clinical evaluation, to rule out the cause of acromegaly features which develops in a short period of time. Her sleep rest pattern affected due to disease process and worried about changing of face features. After referral to the services, she started to be followed up regarding endocrinology (medical /U-II), neurosurgery, ophthalmology, and ENT consultations. On physical examination, acromegaly was evident. $\mathrm{BSL}=300 \rightarrow 350 \rightarrow 270 \rightarrow 250 \rightarrow 450 \mathrm{mg} / \mathrm{dl}$. Weight $=$ $53 \mathrm{~kg}$.

Table: Laboratory Results

\begin{tabular}{|l|l|l|}
\hline Labs test & Normal values & Labs Values \\
\hline Glucose (FASTING) & $90-109$ & $84 \mathrm{mg} / \mathrm{dl}$ \\
\hline Growth Hormone (GH) & $2.0-5.0 \mathrm{ng} / \mathrm{ml}$ & $107 \mathrm{ng} / \mathrm{ml}$ \\
\hline Prolactin (PRL) ranging (III) & $5.18-26.53$ & $15.95 \mathrm{ng} / \mathrm{ml}$ \\
\hline TSH & & $0.388 \mathrm{uIU} / \mathrm{ml}$ \\
\hline T4 (serum) & $5.5-11.0$ & 4.7 \\
\hline ACTH & & Normal \\
\hline Cortisole & & Normal \\
\hline
\end{tabular}

All routine blood labs values normal in range. Anti-nuclear factors: Negative. Magnetic resonance imaging (MRI) done (February 12, 2019) protocol plain- T1W1-12W1 (axial, sagittal, and coronal) depicted a pituitary gland is enlarge measuring $(21 \mathrm{x}$ $22 \mathrm{~mm}$ ), appearing is on T1W1, hypo on T2W1. MRI suggested of bulky pituitary gland possibly of macroadenoma should be considered. MRI imaging rereporting from Shaukat Khanum Memorial Cancer hospital, showing large pituitary mass suggest pituitary macroadenoma. Computerized Tomography of Para Nasal Sinuses shows Sino-nasal Polyposis. Endoscopic histopathology report showing the result of extensive infarcted tissue with non-septate branching fungal hyphae.

Mechanism of infectious, significantly the sphenoid sinusitis can be due to infection of bacterial or fungal, and the risk of hostile fungal sinusitis, especially in patients who are immunocompromised and existing with acute complications of sinusitis. Visual symptoms, including vision loss due to hyper pituitary adenoma [6].

Medically treated with, Tab Metformin 500mg/TDS, Tab Itraconazole 100mg/BD, Tab Thyroxin 25mg/OD, Insulin " $\mathrm{R}$ " according to sliding scale, Hivit-spray 1puff/both nostrils/TDS, Tab Deltacortil 2+2, Tab Vorif 200mg, Cap Sporanox $100 \mathrm{mg} / \mathrm{BD}$. Treatment was ongoing and planned for Trans-sphenoidal surgical procedure.

\section{DISCUSSION}

Pituitary aspergillus is very extremely uncommon condition which occurs in almost exclusively in immunocompromised patients [7]. Pituitary aspergillus infection shows a variability of appearances signs and symptoms when entering the sphenoid sinus and nasal cavity [8]. Endocrine disorders not involving the gonads, but strongly influence the reproductive functions. The surgical procedure is suitable treatment for those patients which they are presented with visual field deficits because it suitable for immediate decompression of the optic chiasm [9]. The combine radiation treatment may be more beneficial for patients to treat from further visual injury. Furthermore, the effective treatment of fungal seller abscess is endoscopic trans-sphenoidal surgery [10].

The optic chiasm is a key anatomical arrangement of erection along the visual pathway, situated at the intersection between the optic nerves and regions. A wide range of diseases can affect the optic chiasm and its adjacent deliberate region at the base of the brain [11]. It has been endeavoring to highlight the importance of sound clinical evaluation and multidisciplinary cooperation (neurosurgery, otorhinolaryngology, ophthalmology, and endocrinology) in the diagnosis and (neurosurgery, otorhinolaryngology, anesthesiology, endocrinology, and radiation oncology) in the management of a rare clinical entity through this case report [12]. 
Uncertainty one is faced with an uncommon seller lesion, including hypo-intensity on T2WI, a peripheral contrast enhanced circumference, sphenoid sinusitis and the possibility of aspergillus infection [6]. Early diagnosis and early inception of treatment in acromegalic patients can prevent the progression of cardiovascular illness and diminish the risk of unexpected death [13].

\section{CONCLUSION}

Endocrine disorders lead to disfunction of the reproductive functions. As a described in the literature reviews pituitary aspergillus is very rare condition which occurs in immunocompromised patients. Antifungal medication Voriconazole preferred after surgery, and surgical treatment suggested for those patients which diagnosed with visual field deficits the reason is to, it allows for immediate decompression of the optic chiasm. Aspergillus seller abscess essential considered in the differential diagnosis of a seller mass, especially in the immune deficiency patients.

Even though, the accurate diagnosis of Aspergillus seller abscess can only be resolute by histopathological investigations, MRI and CT remain the best methods for pre-operative diagnosis. In this case presentation, treatment is on continue in the light of trans-sphenoidal surgical procedure.

Conflicts of Interest: No conflicts of interest declared by authors.

Financial Disclosure: The authors declared that no financial support received in this case study.

\section{REFERENCES}

1. Al-Mendalawi, M. (2018). Pituitary aspergillosis: A report and review of the literature. Neurology India, 66(5), 1525-1525.

2. Brue, T., \& Castinetti, F. (2016). The risks of overlooking the diagnosis of secreting pituitary adenomas. Orphanet journal of rare diseases, 11(1), 135.

3. Chang, A. Y., \& Auchus, R. J. (2019). Endocrine disturbances affecting reproduction. In Yen and
Jaffe's Reproductive Endocrinology (pp. 594-608). Content Repository Only!.

4. Divyashree, S., Karthik, R., Prabhu, K., \& Chacko, G. (2018). Pituitary aspergillosis-A report and review of the literature. Neurology India,66(4), 1176.

5. Hong, W., Liu, Y., Chen, M., Lin, K., Liao, Z., \& Huang, S. (2015). Secondary headache due to aspergillus sellar abscess simulating a pituitary neoplasm: case report and review of literature. SpringerPlus, 4(1), 550.

6. Li, H., Gong, X., Baidya, A., \& Lu, Z. (2019). An unusual case of pituitary fossa aspergillus abscess in AIDS patient mimicking pituitary adenoma: Case report and literature review. Radiology of Infectious Diseases, 6(1), 41-45.

7. Lim, J. C., Rogers, T. W., King, J., \& Gaillard, F. (2017). Successful treatment of pituitary sella Aspergillus abscess in a renal transplant recipient. Journal of Clinical Neuroscience, 45, 138-140.

8. Meier, J. C., Scangas, G. A., Remenschneider, A. K., Sadow, P., Chambers, K., Dedmon, M., ... \& Gray, S. T. (2016). Skull base erosion and associated complications in sphenoid sinus fungal balls. Allergy \& Rhinology, 7(4), ar-2016.

9. Monteiro, A., Agnoletto, G. J., Granja, M. F., BitIvan, E. N., \& Sauvageau, E. (2019). Basilar Occlusion and Rupture Secondary to Rare Fungal Sinusitis. World neurosurgery, 125, 217-221.

10. Nicholas, S. E., Salvatori, R., Quinones-Hinojosa, A., Redmond, K., Gallia, G., Lim, M., ... \& Kleinberg, L. (2018). Deferred radiotherapy after debulking of non-functioning pituitary macroadenomas: Clinical outcomes. Frontiers in oncology, 8 .

11. Pekic, S., Miljic, D., \& Popovic, V. (2018). Infections of the Hypothalamic-Pituitary Region. In Endotext [Internet]. MDText. com, Inc.

12. Singh, I., Sharma, S. A., Dutta, S. G. S., Kaur, G., \& Phogat, D. (2018). A rare case of invasive pituitary tumor mimicking nasal mass. Journal of Marine Medical Society, 20(2), 168.

13. Zaccagna, F., Pizzuti, V., Barone, D. G., Siotto, P., Saba, L., Raz, E., ... \& Massoud, T. F. (2019). In and Around the Optic Chiasm: A Pictorial Review of Neuroimaging. Neurographics, 9(1), 1-17. 